\title{
STUDI IDENTIFIKASI DAN KEANEKARAGAMAN JENIS IKAN YANG TERTANGKAP DI PERAIRAN DAM BETUK KECAMATAN TABIR LINTAS KABUPATEN MERANGIN
}

\author{
Kasmawati, Rini Hertati, Djunaidi \\ Jurusan Pemanfaatan Sumberdaya Perikanan Fakultas Perikanan \\ Universitas Muara Bungo
}

\begin{abstract}
ABSTRAK
Penelitian tentang keanekaragaman jenis ikan di DAM Betuk merupakan sebuah upaya untuk menunjang kepentingan pelestarian jenis ikan dan sebagai salah satu imformasi awal pertimbangan dalam kebijakan pengelolaan kawasan karena masih terbatasnya data base mengenai jenis ikan yang terdapat di DAM Betuk.

. Tujuan yang ingin di capai dalam penelitian ini adalah untuk mengidentifikasi dan keanekaragaman jenis ikan yang tertangkap di Perairan Dam Betuk Desa Tambang Baru Kecamatan Tabir Lintas Kabupaten Merangin.

Metode penelitian yang digunakan Metode Survei dan eksperimen dengan melakukan Penangkapan Ikan dengan menggunakan 3 jenis alat tangkap di antaranya, Jala Tebar,Bubu, dan Pancing kemudian Ikan yang didapatkan diidentifikasi dan diklasifikasikan berdasarkan pada buku acuan Saanin (1984) Jilid I dan II Setelah di identifikasi sampel ikan di foto.

Berdasarkan Dari Hasil Penelitian Jenis -jenis ikan yang tertangkap di sungai Perairan Dam Betuk antara lain: Ikan Gabus (Channa gachua), Nalis, (Labio barbus lineatus), Kepyur (Barbodes lateristiga), Puyu (Anabas testudineus), Masai (Mystacoleucus marginatus), Puyou (Osteochilus waandersii) Baung (Hemibagrus sp), Tilam (macrognatus culatus).

Indeks keanekaragaman jenis ikan pada masing-masing stasiun yakni :Stasiun I Satu Kilo meter $(\mathrm{Km})$ dari Bendungan Dam Betuk kearah hulu Perairan Dam Betuk sebesar 1.18 Stasiun II di Pertengahan Perairan Dam Betuk sebesasar 1.64 Stasiun III di area Bendungan Dam Betuk sebesar 1.74 yang berarti tingkat Keanekaragaman (Hi) jenis Ikan di Perairan Dam Betuk masuk dalam kategori Sedang.
\end{abstract}

\section{Kata Kunci : Eksperimen, Identifikasi Ikan, Keanekaragaman Ika,n Dam Betuk}

\section{PENDAHULUAN}

Kehadiran suatu populasi ikan di suatu tempat dan penyebaran (distribusi) spesies ikan di muka bumi ini selalu berkaitan dengan masalah habitat dan sumberdayanya. Keberhasilan populasi tersebut untuk dapat hidup dan bertahan pada habitat tertentu, tidak terlepas dari penyesuaian atau adaptasi yang dimiliki anggota populasi tersebut. Perairan merupakan habitat bagi ikan dalam proses pembentukan struktur tubuh ikan, proses pernafasan, cara pergerakan, cara memperoleh makanan, reproduksi dan lain-lain. Kaji banding karakter morfologi baik secara internal maupun eksternal dapat menjadi acuan dalam bidang ichtiology dan rekayasa genetika. Pengenalan struktur ikan tidak terlepas dari morfologi ikan yaitu bentuk luar ikan yang merupakan ciri-ciri yang mudah dilihat dan diingat dalam mempelajari jenisjenis ikan. Morfologi ikan sangat berhubungan dengan habitat ikan tersebut di perairan. (Rohansyah, dkk., 2010). 
Partisipasi sebagai suatu konsep dalam pengembangan masyarakat, digunakan secara umum dan luas. Partisipasi Masyarakat adalah keikutsertaan masyarakat dalam proses pengidentifikasi masalah dan potensi yang ada di masyarakat, pemilihan dan pengambilan keputusan tentang alternatif solusi untuk menangani masalah, serta keterlibatan masyarakat dalam mengevaluasi perubahan.( Finna R, 2010).

Luas perairan umum di Kabupaten Merangin seluas 5.520 Ha yang terdiri dari perairan Rawa. Danau, Dam, dan Sungai. Wilayah Kabupaten Merangin banyak dialiri sejumlah Sungai kecil, sedang dan besar di berbagai penjuru.beberapa sungai yang ada di Kabupaten Merangin antara lain adalah sungai Tabir. Batang Meragin, Batang Teletam, Batang Mesumai, Sungai Menyabu dan sejumlah besar terbagi dalam anak-anak sungai kecil dan sedang (Badan Pusat Stasistik Merangin, 2014).

Dam Betuk merupakan suatu perairan yang banyak dimanfaatkan oleh beberapa sektor seperti Pertanian, Perikanan, Pariwisata dan juga merupakan sumber air minum masyarakat di Kabupaten Merangin. Adanya berbagai aktivitas manusia disekitar perairan Dam Betuk akan memberikan dampak yang negatif terhadap ekosistem perairan Dam Betuk, sehingga perairan Dam Betuk akan mengalami perubahan-perubahan ekologis dimana kondisinya sudah berbeda degan kondisi alami yang semula.

Penelitian tentang keanekaragaman jenis ikan di DAM Betuk merupakan sebuah upaya untuk menunjang kepentingan pelestarian jenis ikan dan sebagai salah satu imformasi awal pertimbangan dalam kebijakan pengelolaan kawasan karena masih terbatasnya data base mengenai jenis ikan yang terdapat di DAM Betuk. Maka perlu di lakukan penelitian mengenai "Identifikasi dan keanekaragaman Jenis Ikan Yang Tertangkap di Perairan Dam Betuk Desa Tanbang Baru Kecamatan Tabir Lintas Kabupaten Merangin”.
Penelitian ini dilaksanakan pada bulan November 2017 sampai dengan bulan April 2018. Yang bertempat di Perairan Dam Betuk, Desa Tambang Baru Kecamatan Tabir Lintas Kabupaten Merangin.

\section{METODE PENELITIAN}

Berdasarkan tujuan penelitian yang akan dicapai dan metode penelitian yang akan digunakan yaitu untuk data primer dengan cara observasi langsung dilapangan dan melakukan wawancara kepada nelayan setempat sebagai sumber informasi langsung yang ada dilapangan, serta data sekunder diperoleh dari dinas dan instansi terkait dan hasil tangkapan nelayan sekitar Perairan Dam Betuk serta referensi atau hasil penelitian maupun jurnal penelitian.

Dalam penentuan stasiun penelitian ini digunakan Metode Purposive Sampling yaitu penentuan stasiun penelitian dilakukan berdasarkan tujuan dengan memperhatikan berbagai pertimbangan kondisi dan keadaan tempat penelitian atau Karakteristik seperti kondisi dominan aktivitas masyarakat di perairan Dam Betuk dan lain-lain.

Populasi dalam penelitian ini adalah semua jenis ikan yang tertangkap di Perairan Dam Betuk. Sedangkan sampel dalam penelitian ini adalah perwakilan setiap jenis ikan yang tertangkap di hulu, pertengahan dan muara, atau tiap-tiap Stasiun di Perairan Dam Betuk, Desa Tambang Baru Kecamatan Tabir Lintas Kabupaten Merangin.

Ikan yang didapatkan diidentifikasi dan diklasifikasikan berdasarkan pada buku acuan Saanin (1984) Jilid I /II dan Kattelat , (1993) . Setelah di identifikasi sampel ikan di foto.

Analisis data mencakup indeks keanekaragaman jenis ikan menurut Shannon dalam Bengen, 2000, dilambangkan dengan (Hi) yang dibatasi sebagai :

$$
\mathrm{Hi}=-\sum_{\mathrm{i}-1}^{\mathrm{I}} \mathrm{N}\left(\frac{\mathrm{ni}}{\mathrm{N}} \log 2 \underset{\mathrm{ni}}{\mathrm{n}-1}\right)=-\sum(p i \log 2 p i)
$$

Dimana : 

$\mathrm{Hi}=$ Indeks keanekaragaman Shannon- Wienner.
$\mathrm{Pi}=$ Perbandingan antara jumlah individu spesies jenis ke- $i$ dengan jumlah total individu (ni / N).
$\mathrm{S}=$ Jumlah spesies.
$\mathrm{Ni}=$ Jumlah individu jenis ke- $i$.
$\mathrm{N} \quad=$ Jumlah total individu.

Kriteria penilaian berdasarkan keanekaragaman jenis adalah :

$\mathrm{Hi}<1$ Ordo : Keanekaragaman rendah. Hi $>1-3$ Genus: Keanekaragaman sedang. $\mathrm{Hi}>3$ - 4 Famili : Keanekaragaman tinggi.

\section{HASIL DAN PEMBAHASAN}

\section{Identifikasi}

Hasil tangkapan selama penelitian pada 3 Stasiun ditemukan sebanyak 8 Jenis Ikan,selanjutnya ikan yang tertangkap di tiga Stasiun Perairan Dam Betuk di bawa Kelaboratorium Biologi Universitas Muara Bungo untuk di identifikasai. kholis dan hertati dalam modul praktikum biologi perikanan, 2018 mengatakan bahwa Identifikasi dilakukan dengan mengamati ciri meristik dan morpometrik. Setelah diidentifikasi,untuk mengetahui kingdom, famili sampai spesies ikan tersebut, data hasil identifikasi dapat dicocokkan dengan buku identifikasi Saanin atau Kottelat agar dapat diketahui ikan jenis apa yang diteliti atau diamati.

Menempatkan atau memberikan identitas suatu individu melalui prosedur deduktif ke dalam suatu takson dengan menggunakan kunci determinasi. Affandi dalam Nur Laily, 2006, menambahkan bahwa kunci determinasi adalah susunan kalimat dimana pilihan dapat dilakukan diantara dua keadaan berlawanan yang nantinya akan menghasilkan penerimaan salah satu pilihan atau penolakan lainnya. Kunci determinasi yang digunakan merupakan buku sebagai sumber acuan, buku yang digunakan adalah : Taksonomi dan kunci Identifikasi Jilid 1 dan 2 Saanin, 1984.
Identifikasi dalam penelitian ini dilakukan secara morfometrik (mengukur panjang tubuh ikan) dan meristik (menghitung atribut ikan). Sebagai contoh :

Deskripsi meristik dari masai (Mystacoleucus marginatus) D1,9 ; P 1,9 ;Pv 1,6; A 1,8: Li 25; SMB 7; SMBT 5.

Formula di atas berarti ikan ini memiliki 1 jari-jari keras (spine) yang diikuti dengan 9 jari-jari lemah (rays) pada sirip dorsal (D). Terdapat 1 jari-jari keras (spine) yang diikuti dengan 9 jari-jari lemah (rays) pada sirip pectoral (P). Terdapat 1 jari-jari keras (spine) yang diikuti dengan 6 jari-jari lemah (rays) pada sirip pelvic $(\mathrm{Pv})$. Terdapat 1 jari-jari keras (spine) yang diikuti dengan 8 jari-jari lemah (rays) pada sirip anal (A). Terdapat 25 sisik literal line (Li). Terdapat 7 Jumlah sisik Melintang Badan (SMB). Dan 5 sisik melintang batang ekor (SMBt).

Jari-jari keras yang umumnya berduri ditulis dengan angka Romawi, sementara jari-jari lemah yang umumnya bercabang ditulis dengan angka Arab. (Kottelat dalam Sukmono,T 2017).

Langkah identifikasi Menuju Ordo, Famili, Genus, Species.

Setelah melakukan deskripsi meristik dan morfotrik dilakukan pencocokan menggunakan buku acuan buku identifikasi Saanin atau Kottelat. Hasil penelitian terdapat 4 ordo, 5 famili, dan 8 genus yang terdiri dari 8 spesies.

terdapat 8 jenis ikan yang berhasil di tangkap di Stasiun Perairan Dam Betuk Kabupaten Merangin Propinsi Jambi sebagian besar termasuk ke dalam famili Cyprinidae dengan jumlah anggota sebanyak 4 jenis, kemudian famili bagridae, Channadae, Anabantidae, Mastacembelidae, masing masing 1 jenis. Besarnya jumlah anggota famili Cyprinidae yang ditemukan, disebabkan famili ini merupakan famili ikan air tawar yang terbesar di setiap tempat di dunia, kecuali Australia, Madagaskar, Selandia Baru dan Amerika Selatan (Kottelat et al, Dalam Afreni $\mathrm{H}, 2004)$.

Hasil tangkapan selama penelitian pada 3 Stasiun ditemukan sebanyak 8 Spesies terdiri dari 4 Ordo 5 Famili dan 8 Genus. Sedangkan 
menurut hasil wawancara langsung dengan petani/nelayan pada masing-masing Stasiun di ternyata selama dalam tahun 2018 telah ditemukan atau tertangkap nelayan sebanyak 16 jenis ikan atau $12 \%$ dari ikan lokal air tawar Propinsi Jambi.

Secara umum jumlah jenis ikan pada lokasi penelitian relatif rendah jika dibandingkan dengan jenis ikan yang ada di perairan tawar Propinsi Jambi sebanyak 131 Jenis. Masih sedikitnya jumlah jenis hasil tangkapan selama penelitian ini di karenakan .

> Waktu penelitian atau musim yang relatif singkat dan sedikit (hanya pada musim hujan).

Jumlah dan Jenis alat tangkap yang terbatas (hanya 3 alat tangkap).

$>$ Habitat ikan termasuk sungai bagian huluan hingga pertengahan dengan bentuk dasar sungai berpasir dan berlumpur, sehingga jenis ikan yang ditemukan jenis - jenis ikan yang hidup di perairan dengan arus deras hingga tenang..

$>$ Kemungkinan telah terjadi penurunan jumlah populasi ikan di Perairan DAM Betuk Kabupaten Merangin Propinsi Jambi. Menurunnya jumlah populasi ikan di Sungai menyebabkan peluang tertangkapnya berbagai jenis ikan menjadi lebih kecil (Yustina dalam Afreni H, 2004).

$>$ Luas area dan daerah peangkapan yang terbatas $(2000 \mathrm{~m} /$ Stasiun $)$.

hal ini selaras dengan pendapat Watoon,dalam Budiyono, 2011, bahwa keanekaragaman jenis ikan sungai tergantung pada dua faktor. Pertama, peningkatan jumlah mikro habitat akan dapat meningkatkan keragaman. Kedua, area yang lebih luas sering memilki habitat yang lebih besar dibanding dengan area yang lebih sempit.

\section{Nilai Keanekaragaman Jenis Ikan (Hi)}

Menurut Soegianto dalam Muhammad J, Emiyarti dan Syamsul K, 2013, bahwa indeks keanekaragaman jenis
(Hi) adalah indeks yang menunjukkan banyak tidaknya jenis dan individu yang ditemukan pada suatu perairan. Selanjutnya menurut Fachrul dalam Muhammad J, Emiyarti dan Syamsul K, 2013, menjelaskan bahawa indeks keanekaragaman (indeks of diversity) berguna dalam mempelajari gangguan faktor-faktor lingkungan (abiotik) terhadap suatu komunitas atau untuk mengetahui suksesi atau stabilitas suatu komunitas. Tujuan utama teori informasi Shannon-Wienner adalah untuk mengukur tingkat keteraturan dan ketidakteraturan dalam suatu sistem.

Nilai indeks Keanekaragaman Jenis Ikan (Hi) yang tertangkap selama penelitian di tiga Stasiun Perairan Dam Betuk berdasarkan Indeks Shannon dapat dilihat pada Tabel 2. berikut ini :

Tabel 1. Nilai Keanekaragaman Jenis Ikan (Hi).

\begin{tabular}{ccccc}
\hline No & \multicolumn{1}{c}{ Tanggal } & \multicolumn{3}{c}{ Nilai Indeks Keanekaragaman (Hi) } \\
\hline $\begin{array}{l}12-20 \\
\text { Februari } \\
2018\end{array}$ & $\begin{array}{l}\text { ST I } \\
\text { Dam Betuk }\end{array}$ & $\begin{array}{c}\text { ST II } \\
\text { Dam Betuk }\end{array}$ & $\begin{array}{c}\text { ST III } \\
\text { Dam Betuk }\end{array}$ \\
\hline & & 1,18 & 1.64 & 1.44 \\
\hline
\end{tabular}

Sumber : Data primer diambil bulan Februari 2018

Berdasarkan hasil perhitungan nilai Indeks Keanekaragaman pada Tabel 2. tersebut di atas, bahwa kisaran nilai Indeks Keanekaragaman jenis ikan (Hi) yang tertangkap selama penelitian di tiga Stasiun Perairan Dam Betuk dimana Indeks tertinggi ditemui pada Stasiun III dengan nilai indeks 1,74 , Berada di Area Bendungan Dam Betuk dengan luas alera $2000 \mathrm{M}^{2}$. Lebih tingginya nilai indeks keanekaragaman (Hi) Stasiun III dibanding Stasiun lain (Stasiun 1 dan 2) di karenakan Lokasi ini terdapat Aktifitas Masyarakat seperti Budidaya Ikan di Keramba Jaring Apung, sehingga banyaknya sumber makanan.

Stasiun I. Stasiun ini menurun di karenakan terdapat beberapa aktivitas masyarakat seperti adanya penambangan emas baik secara modern maupun Tradisional di bagian hulu Perairan Dam Betuk.

Stasiun II. sudah tercemar dikarnakan terdapat beberapa aktivitas masyarakat seperti kekeruhan air akibat penambangan emas di huluan sungai yang mengendap di bagian pertengahan, sehingga mempengaruhi 
ekosistem kehupan ikan di Perairan Dam Betuk.

Kepadatan Populasi, Kepadatan Relatif dan Frekuensi Kehadiran

Berdasarkan hasil sampel ikan yang tertangkap pada lampiran 3 dan Tabel 4.6. dapat disajikan pada rekap hasil perhitungan Kepadatan Populasi, Kepadatan Relatif, dan Frekuensi Kehadiran pada Tabel 3. dibawah ini.

Tabel 2. Rekap Hasil Perhitungan Kepadatan Populasi, Kepadatan Relatif, dan Frekuensi Kehadiran.

\begin{tabular}{llccc}
\hline \multirow{2}{*}{ No } & \multirow{2}{*}{ Spesies } & $\mathrm{KP}$ & $\mathrm{KR}$ & $\mathrm{FK}$ \\
\cline { 4 - 5 } & & $\%$ & $\%$ \\
\hline 1 & Anabas testudineus & 0,004 & 15,39 & 100 \\
2 & Barbodes lateristiga & 0,004 & 15,39 & 66 \\
3 & Channa striata & 0,0025 & 9,61 & 66 \\
4 & Hemibagrus SP & 0,0005 & 1,92 & 33 \\
5 & Labiobarbus lineatus & 0,003 & 11,54 & 66 \\
6 & $\begin{array}{l}\text { Mastacembelus } \\
\text { erythrotaenia }\end{array}$ & 0,003 & 11,54 & 66 \\
7 & $\begin{array}{l}\text { Mystacoleucus } \\
\text { marginatus }\end{array}$ & 0,008 & 30,77 & 100 \\
8 & Osteochilus waandersii & 0,0005 & 3,84 & 66 \\
\hline & Jumlah & 0,0255 & 100 & \\
\hline
\end{tabular}

Sumber: Data primer diolah Maret 2018

Dari Tabel 3. di diatas dapat dilihat bahwa kepadatan Populasi (KP), Kepadatan Relatif (KR\%), dan Frekuensi Kehadiran (FK). Kepadan Populasi (KP) tertinggi ditemukan 3 Jenis Ikan diantaranya adalah : Masai mystacoleuculus marginatus sebesar 0,008 (individu)/ $\mathrm{m}^{2}$, Kepyur Barbodes lateristiga sebesar 0,004 (individu) $/ \mathrm{m}^{2}$, kemudian disusul oleh jenis Ikan Betok Anabas testudineus sebesar 0,004 (individu) Hal ini di duga bahwa ikan Masai, Kepyur, Betok Pada umumnya ikan perairan umum,yang hidup di sungai kecil hingga besar dengan arus yang sedang hingga tenang. di samping kualitas air yang mendukung untuk habitat hidupnya. Sebaliknya untuk Kepadatan Populasi (KP) terendah terdapat pada beberapa jenis yaitu ikan Baung. Rendahnya Kepadatan
Populasi (KP) kedua jenis ikan tersebut di duga karena, lokasi penelitian tidak sesuai dengan habitat hidupnya atau ketidak mampuannya dalam beradaptasi dengan lingkungan yang kemungkinan sudah mulai tercemar.

Untuk Kepadatan Relatif (KR\%) paling tinggi terdapat pada ikan Masai Mystacoleucus marginatus sebesar 30,76\%. Sedangkan Kepadatan Relatif (KR \%) terendah ditemukan pada ikan Baung Hemibagrus sp sebesar 1,92\%.

Selanjutnya untuk Frekuensi Kehadiran (FK \%) tertinggi atau Absolut di temukan pada 8 jenis ikan yaitu : Ikan Gabus Channa Striata (66 \%). Nalis, Labio barbus lineatus (66\%), Kepyur Barbodes lateristiga (66 \%), Puyu Anabas testudineus (100 \%), Masai Mystacoleucus marginatus (100 \%), Puyou Osteochilus waandersii (66 \%), Baung Hemibagrus sp (33\%), Tilan Mastacembelus erythrotaenia $(66 \%)$.

Frekuensi Kehadiran (FK\%) Tertinggi ditemukan pada jenis ikan Puyu Anabas testudineus (100 \%), Masai Mystacoleucus marginatus (100\%), dan Terendah di temukan pada jenis ikan yaitu, Baung Hemibagrus sp (33\%). Jika dilihat dari Kriteria penilaian berdasarkan keanekaragaman jenis, ShannonWienner, maka Frekuensi Kehadiran (FK\%) Jenis Ikan di perairan Dam Betuk Kabupaten Merangin Propinsi Jambi masuk dalam kategori kehadiran Rendah.

\section{KESIMPULAN}

Berdasarkan hasil penelitian dapat dijelaskan bahwa:

Jenis -jenis ikan yang tertangkap di sungai Perairan Dam Betuk antara lain : Ikan Gabus (Channa gachua) Nalis, (Labio barbus lineatus), Kepyur (Barbodes lateristiga), Puyu (Anabas testudineus), Masai (Mystacoleucus marginatus), Puyou (Osteochilus waandersii), Baung (Hemibagrus sp), Tilam (Mastacembelus erythrotaenia).

Indeks keanekaragaman jenis ikan pada masing-masing stasiun yakni : Stasiun I Satu Kilo meter $(\mathrm{Km})$ dari Bendungan Dam Betuk kearah hulu Perairan Dam Betuk sebesar 1.18 
Desember 2018

Stasiun II di Pertengahan Perairan Dam Betuk sebesasar 1.64 Stasiun III di area Bendungan Dam Betuk sebesar 1.74 yang berarti tingkat Keanekaragaman (Hi) jenis Ikan di Perairan Dam Betuk masuk dalam kategori Rendah.

\section{DAFTAR PUSTAKA}

BP4K Kabupaten Merangin,Panduan Teknis Penyuluhan Tahun 2014

Btorowidjoyo,M. D; Djoko, T \& Eko, M. 1995 . Pengantar Lingkungan Peraiaran dan Budidaya Air. Yogyakarata: Liberty

Budiyono, 2011, Analisis Pengaruh Penambangan Emas dan Pasir Terhadap Kualitas Air dan Keanekaragaman Jenis Ikan di Sungai Batang Bungo Kabupaten Bungo. Tensis Pasca Sarjana Universitas Bung Hatta.

Djuhanda, T. 1981. Dunia Ikan. Bandung: Armico

Kent, G. C. 1987 Comparative Anatomy of The Vertebrates. St. Louis-TorontoSanta Clara: Time Mirror/Mosby Colloge Publishing.

Koesbiono. 1989. Dasar-Dasar Ekologi Umum. IPB, Bogor.

Kottelat, M; A. J. Whitten; S. N. Kartikasari \& S. Wirjoatmojo. 1993. Freshwater of Western Indonesia and Sulawesi. London: Periplus Edition.

Kottelat et al 1993. Indonesia merupakan Negara kepulauan dengan tingkat biodiversitas tertinggi setelah Brazil

Krebs C.J. 1971. Ecology, The Experimental Analysis of Distribusi and Abundance. Harper and Rows Publiser.

Krebs dalam Gonawi. Perairan yang tercemar umumnya kekayaan jenis relatip Sangat rendah.

Mochamad Idrawan, 2007: 16-18. Tingkatan Keanekaragaman Hayati.

Saanin, H. 1984. Taksonomi dan kunci Identifikasi Ikan. Bigor: Bna Cipta. 